\title{
The Influence of Visual Objects and Music on Anxiety Levels of Breast Cancer Patients Scheduled to Experience Chemotherapy for the First Time: A Prospective Randomized Clinical Study
}

Yakup iriagac ( $\square$ yakupiriagac@hotmail.com )

Tekirdag Namik Kemal University: Tekirdag Namik Kemal Universitesi https://orcid.org/0000-0001-

7411-1705

Eyyup Cavdar

Tekirdağ Namık Kemal Üniversitesi: Tekirdag Namik Kemal Universitesi

Kubilay Karaboyun

Tekirdag Namik Kemal University: Tekirdag Namik Kemal Universitesi

Okan Avci

Tekirdağ Namık Kemal Üniversitesi: Tekirdag Namik Kemal Universitesi

Nehir Tuna

Ege Cortex Psychological Counselling Center

Erdogan Selcuk Seber

Tekirdağ Namık Kemal Üniversitesi: Tekirdag Namik Kemal Universitesi

\section{Research Article}

Keywords: breast cancer, chemotherapy, anxiety, music

Posted Date: November 9th, 2021

DOI: https://doi.org/10.21203/rs.3.rs-1055951/v1

License: (a) (i) This work is licensed under a Creative Commons Attribution 4.0 International License.

Read Full License 


\section{Abstract}

Objective

To investigate the influence of music together with attractive visual objects as an ambiance in the waiting room on anxiety levels of breast cancer patients scheduled to receive chemotherapy in outpatient setting for the first time.

Material and Method

Breast cancer patients planned to receive adjuvant or neoadjuvant chemotherapy for the first time between November 1st, 2020 and July 31st, 2021 were included. Two designs, including a standard waiting room (StWR) and an intervention waiting room (IWR) that was created by adding music and visual objects to the standard room were constructed. These 2 designs were repeated sequentially in monthly periods and a total of 104 patients with 52 in each group were randomized. The State Trait Anxiety Inventory (STAI) and Hospital Anxiety and Depression Scale (HADs) were used for assessments. Results of the patients in StWR and IWR groups were compared.

Results

Both HADs anxiety and STAl-state anxiety scale scores were lower in patients who waited in IWR compared to those who waited in StWR ( $p=0.041, p=0.012$, respectively). In patients in the IWR group, mean heart rate was lower by $7.6 \mathrm{bpm}(p=0.009)$. No difference was found between the groups with regard to HADs depression score and STAl-trait anxiety score $(p=0.305, p=0.535$, respectively). For all patients, HADs anxiety scale $(r=0.400, p=<0.001)$ and STAl-state anxiety scale $(r=0.475, p=<0.001)$ scores increased as the waiting time increased.

Discussion and Conclusion

The present study is the first to investigate the influence of adding music together with attractive visual objects to the standard ambiance of the chemotherapy waiting room on anxiety levels of breast cancer patients. We propose that introduction of paintings, artificial plants, and music to the ambiance of the waiting room has a significantly positive effect on alleviating anxiety levels of cancer patients waiting for chemotherapy.

\section{Introduction}

Anxiety, which was first described by Sigmund Freud, is a feeling of danger against moral, neurotic and objective risks [1]. During anxiety, the individual feels alarmed and experiences a sense of expecting something negative. Spielberg and colleagues divide anxiety into two as state anxiety and trait anxiety. While state anxiety is a mood related with "that moment" induced by environmental stress factors, trait anxiety is a "long standing" mood that arises independently from immediate risks and continues lifelong, affecting the behaviors of the individual [2,3]. 
Breast cancer is among the most common cancer types in women and causes approximately $15 \%$ of cancer-related deaths in women [4]. Breast cancer patients feel intensive psychological stress at the time of diagnosis, and anxiety and depression are common in these patients $[5,6]$.

Breast cancer patients experience different levels of anxiety at different stages of their treatment [7]. Anxiety and depression have harmful effects on several components of quality of life in these women receive adjuvant therapy for breast cancer [8]. Furthermore, psychological stress may lead to an increase in side effects such as chemotherapy-related nausea and vomiting $[8,9]$. Regardless of the reason, delayed treatment inevitably leads to increased morbidity and mortality $[10,11]$. Psychological interventions are thought to reduce anxiety and increase treatment adherence [12]. For a successful treatment process, necessary measures should be taken and reducing anxiety should be addressed as a component of the treatment.

Environments the patients scheduled to receive chemotherapy for the first time are exposed to may be effective on stress levels. While urban environments have negative effects on individuals, natural environmental stimuli that do not cause a threat have stress-reducing and regenerative effects [13] . Today, visual and audial interventions are commonly used in hospital environment due to their positive effects. However, the influence of visual and audial designs of waiting rooms have not been sufficiently investigated in breast cancer patients who are to receive adjuvant or neoadjuvant chemotherapy for the first time.

In the present study, it was aimed to investigate the influence of a visual and audial ambiance of the waiting room on the anxiety breast cancer patients experience before their first chemotherapy in an outpatient setting.

\section{Material And Methods}

\subsection{Participants}

Breast cancer patients scheduled to receive neoadjuvant or adjuvant chemotherapy between November 1st, 2020 and July 31st, 2021 were included in the study. Patients over 18 years of age who would receive a cyclophosphamide-epirubicin regimen as initial therapy were. Patients who had metastatic breast cancer, diagnosis or suspicion of epilepsy, history of previous chemotherapy, vision or hearing loss, who would not be able to receive treatment via peripheral intravenous route and who did not provide consent for participation were excluded.

This study conformed to the provisions of the 1995 Declaration of Helsinki. All patients provided informed consent, and the Local Ethics Committee granted formal approval to this prospective randomize study (approval no: 2020.188.07.21 on July 30th, 2020). The project was registered to clinicaltrials.gov with the ID number NCT04839835.

\subsection{Study design and procedure}


The present study was designed as a prospective, randomized, controlled, open-label study. Two designs were created as the standard waiting room (StWR) and the intervention waiting room (IWR), with the latter including music and visual objects. These two designs were repeated with monthly periods (the last working day of each month) and a total of 104 patients, with 52 in each group, were randomized to waiting rooms. The study was started by including patients into the StWR group. (Figure 1)

Informed consent was obtained from the patients when they arrived at the chemotherapy outpatient clinic, and they were asked to wait half an hour at minimum. At the beginning of the examination, patients were invited to the examination area after their heart rate had been measured by the nurses and Hospital Anxiety and Depression Scale (HADs) and State Trait Anxiety Inventory (STAI) were filled out by the oncologist through face-to-face interviews. After these measurements, other standard examinations were performed, and the patients were taken to chemotherapy infusion section.

\subsection{Experimental Design of the Waiting Room and Intervention}

\subsubsection{Audial intervention}

Four speakers were installed into the ceiling by a professional team so that the music could be heard equally from each point of the waiting room. One Magicvoice ${ }^{\circledR}$ MV-510 50 Amplification was used for computer connection of the speakers. Patients were made to listen to the music with the original name of "3-Hour Relaxing Guitar Music: Meditation Music, Instrumental Music, Calming Music, Soft Music" and can be reached at https://www.youtube.com/watch?v=ss7EJ-PW2Uk through internet connection by using a computer.

\subsubsection{Visual intervention}

Four images with blue and green dominancy that were considered to lead to relieving and without images such as mountains that do not stimulate unconscious restrictive feelings were downloaded from pixabay.com (id numbers: 3369304, 2135026, 1993704, 2413078) under free license. Afterwards, printing measuring $150 \times 100 \mathrm{~cm}$ was done on cotton canvas by a professional team. Paintings were placed onto both walls that could be completely illuminated by spotlights so as to be at equal distances to perspectives. For isolation purposes, artificial bamboo plants measuring $200 \mathrm{~cm}$ in width and $50-90 \mathrm{~cm}$ in height were placed and interaction with outer stimuli was minimized (Figures 2 and 3 ).

\subsection{Measurements}

\subsubsection{The Hospital Anxiety and Depression Scale (HADs)}

HADs is a reliable self-assessment scale developed for the detection of anxiety and depression status of patients in an outpatient setting. The scale, which was developed by Zigmond and Snaith in 1983, consists of a total of 14 items composed of HADs-A (anxiety, 7 questions) and HADs-D (depression, 7 questions) [14]. All items are scored between 0 and 3 . Each sub-scale yields minimum 0 , and maximum 21 points and there is a positive correlation between higher scores and anxiety-depression. HADs, which 
was translated to Turkish by Aydemir et al. has been reported to be a reliable and valid scale for the Turkish population [15].

\subsubsection{The State-Trait Anxiety Inventory (STAl)}

STAI was first developed by Spielberg in 1970s [16]. It is a reliable assessment questionnaire which consists of two parts as state anxiety and trait anxiety (general feelings). Each part consists of 20 questions. The first sub-scale, STAl-state anxiety, evaluates state anxiety through questioning subjects about how they feel "at the moment". The second sub-scale, STAl-trait anxiety, evaluates how patients "usually" feel. Each answer is scored between 1 and 4 according to symptom severity. The state and trait anxiety subscales are scored separately. The possible score of each sub-scale varies between 20 and 80 , and there is a positive correlation between higher scores and higher anxiety levels. STAI was translated to Turkish and validated by Öner and LeCompte [3].

\subsection{Power Analysis}

In a similar study conducted by using the STAl-anxiety score, Line et al. found approximately 5.6 points of difference between the groups [17]. In sample calculation done by using MedCalc for Windows, version 19.4 (MedCalc software Ltd. Acacialan, 228400 Ostend, Belgium), a sample size of 104 individuals (52 study participants, 52 controls) was found to be sufficient for making a comparison between the groups at $80 \%$ power with $5 \%$ alpha error.

\subsection{Statistical Analyses}

Descriptive statistics were summarized as frequency and percentage for categorical variables and mean and standard deviation for continuous variables. Kolmogorov-Smirnov test was applied to test the normality distribution of all data. Independent samples T-test was used for comparison of normally distributed independent continuous variables, and Mann-Whitney $U$ test was used for non-normally distributed variables. For the comparison of categorical variables, chi-square test (Fisher's exact test when chi-square test was inappropriate) was used. Correlations between data were evaluated with Pearson's correlation analysis or Spearman's correlation analysis (for non-normally distributed data). Statistical analyses were performed using the SPSS Statistic software version 24 (SPSS Inc., Chicago, III) and a $p$-value of $<0.05$ was considered statistically significant.

\section{Results}

\subsection{Patient characteristics}

A total of 104 patients were randomized with 52 in each group. Measurements of all patients were performed with face-to face interviews. Mean age of the patients was $47.4 \pm 8.0$ years and median age was 48 years (min:27, max:60). In our country, minimum wage is approximately 350 USD, and 69 participants $(66.3 \%)$ had a monthly income of $300-600$ USD and most of the patients $(60.6 \%)$ were receiving social support from their spouses (Table 1). 
Mean age of the patients randomized to the StWR group was 46.8 \pm 8.4 years, mean age of those in IWR was $48.0 \pm 7.6$ years, and the groups were statistically similar with regard to age $(p=0.435)$. Groups were distributed homogeneously with regard to treatment type and breast cancer stage $(p=0.539, p=0.642$, respectively). Patients in the IWR group waited for a mean of 37.7 minutes (min:30, max:51) and those in the StWR group waited for a mean of 40.4 minutes (min:30; max:56) before the measurements so that both groups had similar waiting times $(p=0.069)$ (Table 2$)$.

\subsection{Measurement results}

When the groups were compared with regard to HADs anxiety scale scores, the mean score of the StWR group was found to be $9.0 \pm 4.5$ and the mean score of IWR was $6.9 \pm 3.6(p=0.041)$. Mean STAl-state anxiety inventory score was found to be $50.2 \pm 9.8$ in the StWR group and $44.8 \pm 11.5$ in the IWR group $(p=0.012)$. There was no difference between the groups with regard to HADs depression scale score and STAl-trait anxiety inventory score $(p=0.305, p=0.535$, respectively). Mean heart rate was $89.2 \mathrm{bpm}$ in patients in the StWR group, $81.6 \mathrm{bpm}$ in those in the IWR group and the difference was statistically significant $(p=0.009)$ (Table 2).

For all patients, anxiety levels increased as the waiting time increased $(r=0.400, p=<0.001$ for HADs-A, $r=0.475, p=<0.001$ for STAl-state anxiety). There was a positive correlation between waiting times and HADs-A scale scores ( $r=0.315, p=0.023)$, and STAl-state anxiety scores $(r=0.317, p=0.022)$ of the patients in the StWR group. Similarly, there was a positive correlation between waiting times and HADs-A scale scores $(r=0.443, p=0.001)$, and STAI-state anxiety inventory scores $(r=0.568, p=0.000)$ of the patients in the IWR group (Table 3 ).

\section{Discussion And Conclusion}

Anxiety, an affective disorder, is commonly seen in breast cancer patients [18,19]. In studies conducted with breast cancer patients, early intervention to anxiety provide many benefits including improved quality of life, treatment compliance and improved mood [20,21]. In this study, we achieved a positive effect on HADs anxiety measures (2.1 points, $p=0.041)$ and STAl-state anxiety measures (5.4 points, $p=0.012)$ with visual objects and music added to the waiting room ambiance. Recent studies have revealed that increased anxiety leads to an increase in cancer-related mortality in patients under 60 years of age [22]. Therefore, there is a need to relieve the anxiety of patients as a part of cancer treatment.

The influence of music on anxiety has been investigated in patients receiving chemotherapy and music therapy has been proven to reduce anxiety [23-25]. Besides, systematic reviews report that music interventions not only reduce anxiety but also have many positive effects such as reducing pain, fatigue, heart rate and improving quality of life $[26,27]$. In a study from China, breast cancer patients who listened to music during the first 2 chemotherapy cycles following radical mastectomy described less pain compared to those who did not listen to music [28]. In many studies conducted with different patient populations, music therapy was found to have several positive effects on anxiety, pain and 
dissatisfaction [29-31]. Approximately $65 \%$ of the patients who experience chemotherapy want fun activities like music therapy in the waiting room [32].

Different types of studies are available in the literature investigating the effects of music types on anxiety levels of patients. In a study by Malakoutikhah et al., it was found that while pop, Western classical music, and Persian traditional music provided relief in patients from the Iran population, any type of music was found to reduce anxiety [33]. In studies conducted with cancer patients, guitar, piano, and flute music were found to have positive effects on anxiety $[17,34]$. In our literature-based music preference, we selected a music which includes Latin guitar, piano and flute, and used it as an ambiance in the waiting room.

Being subjected to visual objects have been known to have positive effects on stress for many years $[13,35,36]$. In the study of Becker and Dauglas conducted in waiting rooms of gynecology, dermatology and gastro-enterology clinics, the authors have proven the hypothesis that physical attraction may indeed lead to a decrease in anxiety [37]. However, the ambiance they created was not a practical design. Nanda et al. were able to achieve positive effects on the anxiety and stress the patients felt during the waiting time through the ambiance they designed by using only visual elements in the waiting room of the emergency department [38].

Using still art by covering a frame in waiting rooms has positive effects on anxiety and stress through a "window-like" effect [39].Beukeboom et al. obtained a similar effect through artificial nature in a heterogeneous patient population in the radiology department [40]. In our study, in order to create such a "window-like effect", real nature scenic views such as natural coasts and meadows which do not include restrictive elements were used. In order to strengthen the impact of visual effects, artificial plants were also placed. The fact that closed environments do not have sufficient sunlight for nourishment of live plants lead to the decision of choosing artificial plants instead of live ones. In the intervention group where both visual and audial interventions were implemented, HADs-anxiety scale score was detected to be 2.1 points lower $(p=0.041)$ and STAl-state anxiety inventory score was detected to be 5.4 points lower $(p=0.012)$.

Long waiting times were related with increased anxiety in the studies conducted at dentistry and radiology departments $[41,42]$. In our study, there was a positive correlation between waiting times and anxiety levels with correlation coefficients varying between 0.32 and 0.57 (Table 3 ). Independently from the ambiance of the waiting room, pre-treatment waiting times should be shortened in order to anxiety.

There was no difference between the groups with regard to HADS-D score that measures the depression level of the patients $(p=0.305)$. Similarly, there was no difference between the groups with regard to STAItrait anxiety scores that reveal anxiety levels $(p=0.535)$. These results suggest that state anxiety may be reduced through visual and audial interventions to the boring settings where patients wait; however, depression and trait anxiety may not be changed with such interventions. In addition, in the designed waiting room a significant reduction $(7.6 \mathrm{bpm})$ in the heart rate of the patients was achieved $(p=0.009)$. These results are consistent with those which revealed that music reduces heart rate [43]. 
The present study has certain limitations. Although the exposure time to audial factors could be measured, the exact exposure time to visual factors was an unmeasurable factor. In addition, social interaction of the patients with others in the waiting room could not be recorded and this leads to an insufficient measurement of the social support parameter. During waiting times, restrictions of internet or social media use through cell phones was not asked due to ethical principles. The likelihood that interactions through cell phones may have led to different effects on anxiety levels of the patients was another limitation of our study [44]. On the other hand, the fact that visual intervention were easily applicable, did not require professional architectural support and the photos we used being accessible from anywhere worldwide were the strengths of our study.

To the best of our knowledge, this is the first study to investigate the influence of waiting room ambiance on the anxiety level of non-metastatic cancer patients before chemotherapy. Other studies have investigated metastatic patient groups, implemented interventions directly on the patients and not the waiting environment, or the anxiety during chemotherapy was investigated [32,45]. In conclusion, we have concluded that visual and audial interventions in waiting rooms may reduce the anxiety level of patients scheduled to experience chemotherapy for the first time.

\section{Declarations}

Funding: The funding was supported by the authors themselves without the involvement of grant, research scholarship, or any other funding sources.

Conflicts of interest/Competing interests: The authors declare that they have no conflict of interest.

Availability of data and material: Data are held securely by the research team and may be available upon reasonable request and with relevant approvals in place.

Code availability: Not applicable

Authors' contributions: Conception and design: Y.Iriagac, Administrative support: Y.Iriagac, Collection and assembly of data: All authors, Data analysis and interpretation: Y.Iriagac, Manuscript writing: All authors, Final approval of manuscript: All authors, Accountable for all aspects of the work: All authors

Ethics approval: The present study was performed in line with the principles of the Declaration of Helsinki. The Tekirdag Namik Kemal University Ethics Committee granted formal approval to this study (approval no: 2020.188.07.21 on July 30th, 2020).

Consent to participate: Informed consent was obtained from all individual participants included in the study prior to the interview

Consent for publication: Not applicable

Conflict of interest: None 


\section{References}

1. Freud S. The Problem of Anxiety. Read Books Ltd; 2013.

2. Spielberger CD. Assessment of state and trait anxiety: Conceptual and methodological issues. South Psychol. Published online 1985.

3. Oner N, Le Compte A. Süreksiz Durumluk/Sürekli Kaygı Envanteri El Kitabı. İstanbul: Boğaziçi Üniversitesi Yayınevi. Published online 1983.

4. Sung H, Ferlay J, Siegel RL, et al. Global cancer statistics 2020: GLOBOCAN estimates of incidence and mortality worldwide for 36 cancers in 185 countries. CA Cancer J Clin. 2021;71(3):209-249.

5. Chirico A, Lucidi F, Mallia L, D'Aiuto M, Merluzzi T V. Indicators of distress in newly diagnosed breast cancer patients. PeerJ. 2015;3:e1107.

6. Hill J, Holcombe C, Clark L, et al. Predictors of onset of depression and anxiety in the year after diagnosis of breast cancer. Psychol Med. 2011;41(7):1429-1436.

7. Rao MR, Raghuram N, Nagendra HR, et al. Anxiolytic effects of a yoga program in early breast cancer patients undergoing conventional treatment: a randomized controlled trial. Complement Ther Med. 2009;17(1):1-8.

8. So WKW, Marsh G, Ling WM, et al. Anxiety, depression and quality of life among Chinese breast cancer patients during adjuvant therapy. Eur J Oncol Nurs. 2010;14(1):17-22.

9. Schneider SM, Kisby CK, Flint EP. Effect of virtual reality on time perception in patients receiving chemotherapy. Support Care Cancer. 2011;19(4):555-564.

10. Chavez-MacGregor M, Clarke CA, Lichtensztajn DY, Giordano SH. Delayed initiation of adjuvant chemotherapy among patients with breast cancer. JAMA Oncol. 2016;2(3):322-329.

11. Hanna TP, King WD, Thibodeau S, et al. Mortality due to cancer treatment delay: systematic review and meta-analysis. bmj. 2020;371.

12. Andersen BL, Farrar WB, Golden-Kreutz DM, et al. Psychological, behavioral, and immune changes after a psychological intervention: a clinical trial. J Clin Oncol Off J Am Soc Clin Oncol. 2004;22(17):3570.

13. Ulrich RS, Simons RF, Losito BD, Fiorito E, Miles MA, Zelson M. Stress recovery during exposure to natural and urban environments. J Environ Psychol. 1991;11(3):201-230.

14. Zigmond AS, Snaith RP. The hospital anxiety and depression scale. Acta Psychiatr Scand. 1983;67(6):361-370. 
15. Aydemir Ö, Guvenir T, Kuey L, Kultur S. Validity and reliability of Turkish version of hospital anxiety and depression scale. Turk Psikiyatr Derg. 1997;8(4):280-287.

16. Spielberger CD. State-Trait anxiety inventory. Corsini Encycl Psychol. Published online 2010:1.

17. Lin M, Hsieh Y, Hsu Y, Fetzer S, Hsu M. A randomised controlled trial of the effect of music therapy and verbal relaxation on chemotherapy-induced anxiety. J Clin Nurs. 2011;20(7-8):988-999.

18. Hashemi S-M, Rafiemanesh $\mathrm{H}$, Aghamohammadi T, et al. Prevalence of anxiety among breast cancer patients: a systematic review and meta-analysis. Breast Cancer. 2020;27(2):166-178.

19. Jacobsen PB, Bovbjerg DH, Redd WH. Anticipatory anxiety in women receiving chemotherapy for breast cancer. Heal Psychol. 1993;12(6):469.

20. Stark D, Kiely M, Smith A, Velikova G, House A, Selby P. Anxiety disorders in cancer patients: their nature, associations, and relation to quality of life. J Clin Oncol. 2002;20(14):3137-3148.

21. Spiegel D, Riba MB. Managing anxiety and depression during treatment. Breast J. 2015;21(1):97103.

22. Wang $\mathrm{X}$, Wang $\mathrm{N}$, Zhong $\mathrm{L}$, et al. Prognostic value of depression and anxiety on breast cancer recurrence and mortality: a systematic review and meta-analysis of 282,203 patients. Mol Psychiatry. 2020;25(12):3186-3197.

23. Latif Al, Alhidayat NS, Putra SH, Erika KA, Ningrat S, Syahrul S. Effectiveness of music therapy in reducing the level of anxiety among cancer patients undergoing chemotherapy. Enferm Clin. 2020;30:304307.

24. Ferrer AJ. The effect of live music on decreasing anxiety in patients undergoing chemotherapy treatment. J Music Ther. 2007;44(3):242-255.

25. Mondanaro JF, Sara GA, Thachil R, et al. The Effects of Clinical Music Therapy on Resiliency in Adults Undergoing Infusion: A Randomized, Controlled Trial. J Pain Symptom Manage. 2021;61(6):10991108.

26. Bradt J, Dileo C, Magill L, Teague A. Music interventions for improving psychological and physical outcomes in cancer patients. Cochrane Database Syst Rev. 2016;(8).

27. Tsai HF, Chen YR, Chung MH, et al. Effectiveness of music intervention in ameliorating cancer patients' anxiety, depression, pain, and fatigue: A meta-analysis. Cancer Nurs. 2014;37(6):E35-E50.

28. Li X-M, Yan H, Zhou K-N, Dang S-N, Wang D-L, Zhang Y-P. Effects of music therapy on pain among female breast cancer patients after radical mastectomy: results from a randomized controlled trial. Breast Cancer Res Treat. 2011;128(2):411-419. 
29. Cakmak O, Cimen S, Tarhan $\mathrm{H}$, et al. Listening to music during shock wave lithotripsy decreases anxiety, pain, and dissatisfaction. Wien Klin Wochenschr. 2017;129(19):687-691.

30. Hsu K-C, Chen LF, Hsiep PH. Effect of music intervention on burn patients' pain and anxiety during dressing changes. Burns. 2016;42(8):1789-1796.

31. Shabanloei R, Golchin M, Esfahani A, Dolatkhah R, Rasoulian M. Effects of music therapy on pain and anxiety in patients undergoing bone marrow biopsy and aspiration. AORN J. 2010;91(6):746-751.

32. Catania C, De Pas T, Minchella I, et al. "Waiting and the waiting room: How do you experience them?" Emotional implications and suggestions from patients with cancer. J Cancer Educ. 2011;26(2):388-394.

33. Malakoutikhah A, Dehghan M, Ghonchehpoorc A, Afshar PP, Honarmand A. The effect of different genres of music and silence on relaxation and anxiety: A randomized controlled trial. Explore. 2020;16(6):376-381.

34. Krishnaswamy P, Nair S. Effect of music therapy on pain and anxiety levels of cancer patients: A pilot study. Indian J Palliat Care. 2016;22(3):307.

35. Ulrich RS. View through a window may influence recovery from surgery. Science (80-). 1984;224(4647):420-421.

36. Jimenez MP, DeVille N V, Elliott EG, et al. Associations between nature exposure and health: A review of the evidence. Int J Environ Res Public Health. 2021;18(9):4790.

37. Becker F, Douglass S. The ecology of the patient visit: physical attractiveness, waiting times, and perceived quality of care. J Ambul Care Manage. 2008;31(2):128-141.

38. Nanda U, Chanaud C, Nelson M, Zhu X, Bajema R, Jansen BH. Impact of visual art on patient behavior in the emergency department waiting room. J Emerg Med. 2012;43(1):172-181.

39. Frampton SB, Charmel PA. Putting Patients First: Best Practices in Patient-Centered Care. Vol 38. John Wiley \& Sons; 2009.

40. Beukeboom CJ, Langeveld D, Tanja-Dijkstra K. Stress-reducing effects of real and artificial nature in a hospital waiting room. J Altern Complement Med. 2012;18(4):329-333.

41. Coffey PAF, Di Giusto J. The effects of waiting time and waiting room environment on dental patients' anxiety. Aust Dent J. 1983;28(3):139-142.

42. Thu HS, Stutzman SE, Supnet C, Olson DM. Factors associated with increased anxiety in the MRI waiting room. J Radiol Nurs. 2015;34(3):170-174. 
43. Wang X, Zhang Y, Fan Y, Tan X-S, Lei X. Effects of music intervention on the physical and mental status of patients with breast cancer: a systematic review and meta-analysis. Breast Care. 2018;13(3):183-190.

44. Kim MJ, Oh H-K, Lee KC, et al. Effects of an Internet-based informational video on preoperative anxiety in patients with colorectal cancer. Ann Surg Treat Res. 2019;96(6):290-295.

45. Elimimian EB, Elson L, Stone E, et al. A pilot study of improved psychological distress with art therapy in patients with cancer undergoing chemotherapy. BMC Cancer. 2020;20(1):1-11.

\section{Tables}


Table 1: Patient characteristics and demographics $(n=104)$

Age (years)

- Under 50

$58(55.8 \%)$

- Between $50-60$

$46(44.2 \%)$

Marital status

- Married

84 (80.8\%)

$15(14.4 \%)$

- Single

$3(2.9 \%)$

- Divorced

$2(1.9 \%)$

- Widowed

Social support (companion)

- Spouse

$63(60.6 \%)$

- Children

$20(19.2 \%)$

- Others

$18(17.3 \%$

$3(2.9 \%)$

- None

Education status

- Elementary school

$43(41.3 \%)$

- High school

$49(47.1 \%)$

- College or higher

$12(11.5 \%)$

Monthly income (USD)

- $300-600$

$69(66.3 \%)$

- $600-1000$

$24(23.1 \%)$

$11(10.6 \%)$

Page 13/17 
Table 2 : Comparison of patients waiting in the standard waiting room and the intervention waiting room with regard to measurement results and other characteristics

\begin{tabular}{|c|c|c|c|c|c|c|}
\hline & & \multicolumn{2}{|c|}{$\begin{array}{l}\text { Standard Waiting Room } \\
(\text { StWR })(n=52)\end{array}$} & \multicolumn{3}{|c|}{$\begin{array}{l}\text { Intervention Waiting } \\
\text { Room (IWR) }(n=52)\end{array}$} \\
\hline & & Mean $\pm S D / n$ & Median & Mean. $\pm S D / n$ & Median & $\mathrm{p}$ \\
\hline Age (years) & & $46.8 \pm 8.4$ & 47.5 & $48.0 \pm 7.6$ & 49.0 & $\begin{array}{l}0.435 \\
t\end{array}$ \\
\hline \multirow[t]{2}{*}{ Disease stage } & Two & $13(25.0 \%)$ & & $11(21.2 \%)$ & & \multirow{2}{*}{$\begin{array}{l}0.642 \\
\times 2\end{array}$} \\
\hline & Three & $39(75.0 \%)$ & & 41 (78.8\%) & & \\
\hline \multirow[t]{2}{*}{$\begin{array}{l}\text { Social support } \\
\text { (companion) }\end{array}$} & Yes & $50(96.2 \%)$ & & $51(98.1 \%)$ & & \multirow[t]{2}{*}{$\begin{array}{l}0.500 \\
f\end{array}$} \\
\hline & No & $2(3.8 \%)$ & & $1(1.9 \%)$ & & \\
\hline \multirow[t]{2}{*}{ Treatment type } & $\begin{array}{l}\text { Neo- } \\
\text { adjuvant }\end{array}$ & 32 (61.5\%) & & $35(67.3 \%)$ & & \multirow[t]{2}{*}{$\begin{array}{l}0.539 \\
\times 2\end{array}$} \\
\hline & Adjuvant & $20(38.5 \%)$ & & 17(32.7\%) & & \\
\hline $\begin{array}{l}\text { Waiting time } \\
\text { (min) }\end{array}$ & & $40.4 \pm 6.9$ & 38 & $37.7 \pm 5.7$ & 36.5 & $\begin{array}{l}0.069 \\
\mathrm{~m}\end{array}$ \\
\hline \multirow[t]{2}{*}{ HADs } & Anxiety & $9.0 \pm 4.5$ & 8 & $6.9 \pm 3.6$ & 7 & $\begin{array}{l}0.041 \\
\mathrm{~m}\end{array}$ \\
\hline & Depression & $6.5 \pm 4.7$ & 5.5 & $5.7 \pm 4.3$ & 4 & $\begin{array}{l}0.305 \\
\mathrm{~m}\end{array}$ \\
\hline \multirow[t]{2}{*}{ STAI } & $\begin{array}{l}\text { State } \\
\text { anxiety }\end{array}$ & $50.2 \pm 9.8$ & 50.5 & $44.8 \pm 11.5$ & 46.5 & $0.012^{t}$ \\
\hline & $\begin{array}{l}\text { Trait } \\
\text { anxiety }\end{array}$ & $45.1 \pm 9.2$ & 45.5 & $46.1 \pm 6.7$ & 46 & $0.535^{t}$ \\
\hline $\begin{array}{l}\text { Pulse rate (per } \\
\text { min.) }\end{array}$ & & $89.2 \pm 16.0$ & 87.5 & $81.6 \pm 12.9$ & 80 & $\begin{array}{l}0.009 \\
t\end{array}$ \\
\hline
\end{tabular}

Statistical methods: ${ }^{\mathrm{X}}$ : Chi-square, ${ }^{\mathrm{t}}$ : independent sample t-test, ${ }^{\mathrm{f}}$ : Fisher's exact test, ${ }^{\mathrm{m}}$ : Mann Whitney U test, ${ }^{S D}$ : standard deviation 
Table 3: The correlation analysis between HADs-anxiety scale score, STAI-State anxiety score and patient characteristics

Standard Waiting Room $(\mathrm{n}=52)$

Intervention Waiting Room $(\mathrm{n}=52)$

HADs Anxiety

STAI-State Anxiety

HADs Anxiety

STAI-State Anxiety

Scale score Inventory score

Scale score Inventory score

$\begin{array}{llllllll}\mathbf{r} & \boldsymbol{p} & \mathbf{r} & \boldsymbol{p} & \mathbf{r} & \boldsymbol{p} & \mathbf{r} & \boldsymbol{p}\end{array}$

$\begin{array}{lllllllll}\text { Treatment } & 0.075 & 0.595 & 0.025 & 0.860 & 0.034 & 0.809 & 0.048 & 0.737\end{array}$ type
Age
0.051
0.717
0.051
0.718
0.218
0.120
0.050
0.724

Heart rate

0.105

0.459

$-0.006$

0.964

0.104

0.461

0.226

0.107

Waiting

$\begin{array}{lll}0.315 & \mathbf{0 . 0 2 3} & 0.317\end{array}$

0.022

$0.443 \quad 0.001$

0.568

$<0.001$

time

Disease

$0.649<0.001 \quad 0.395$

0.004

$0.647<0.001 \quad 0.610$

$<0.001$

stage

HADs-

Depression

$0.714<0.001 \quad 0.260$

0.062

$0.552<0.001 \quad 0.411$

0.002

STAI State

$0.693<0.001$

$0.812<0.001$

anxiety.

STAI Trait anxiety.

$0.526<0.001 \quad 0.253$

0.071

$0.493<0.001$

0.485

$<0.001$

\section{Figures}




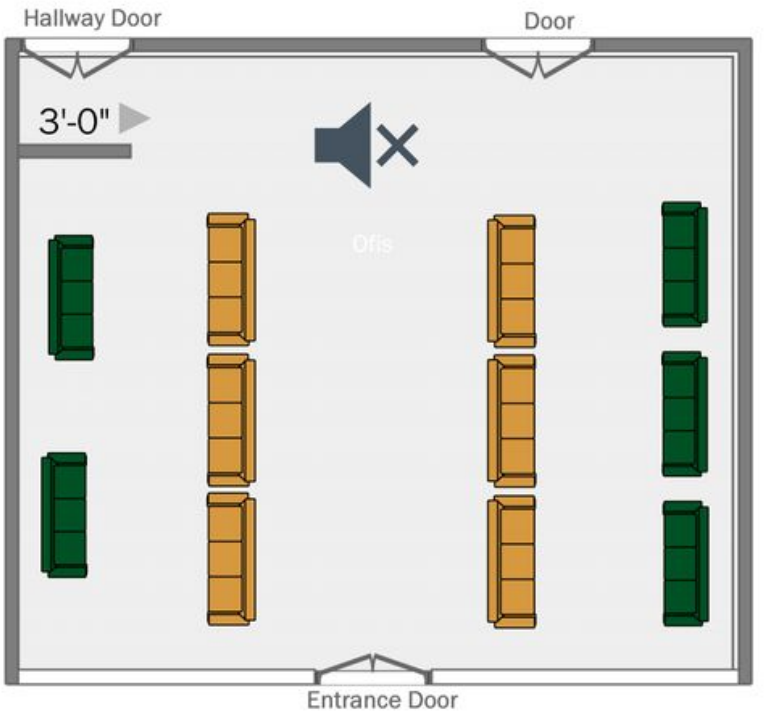

Standard Waiting Room
Monthly Cycle

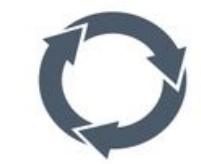

Monthly Cycle

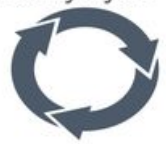

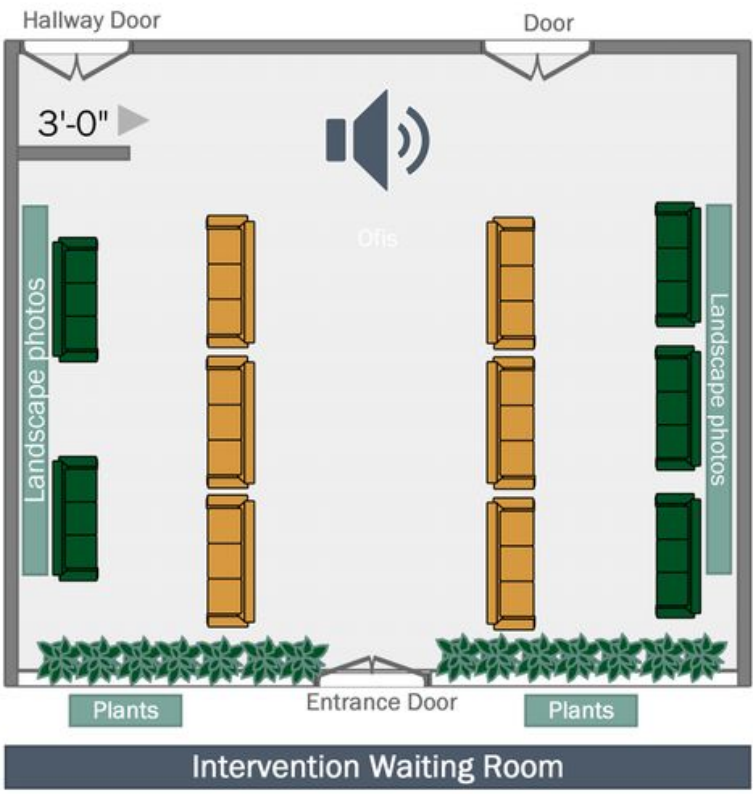

Figure 1

Study design

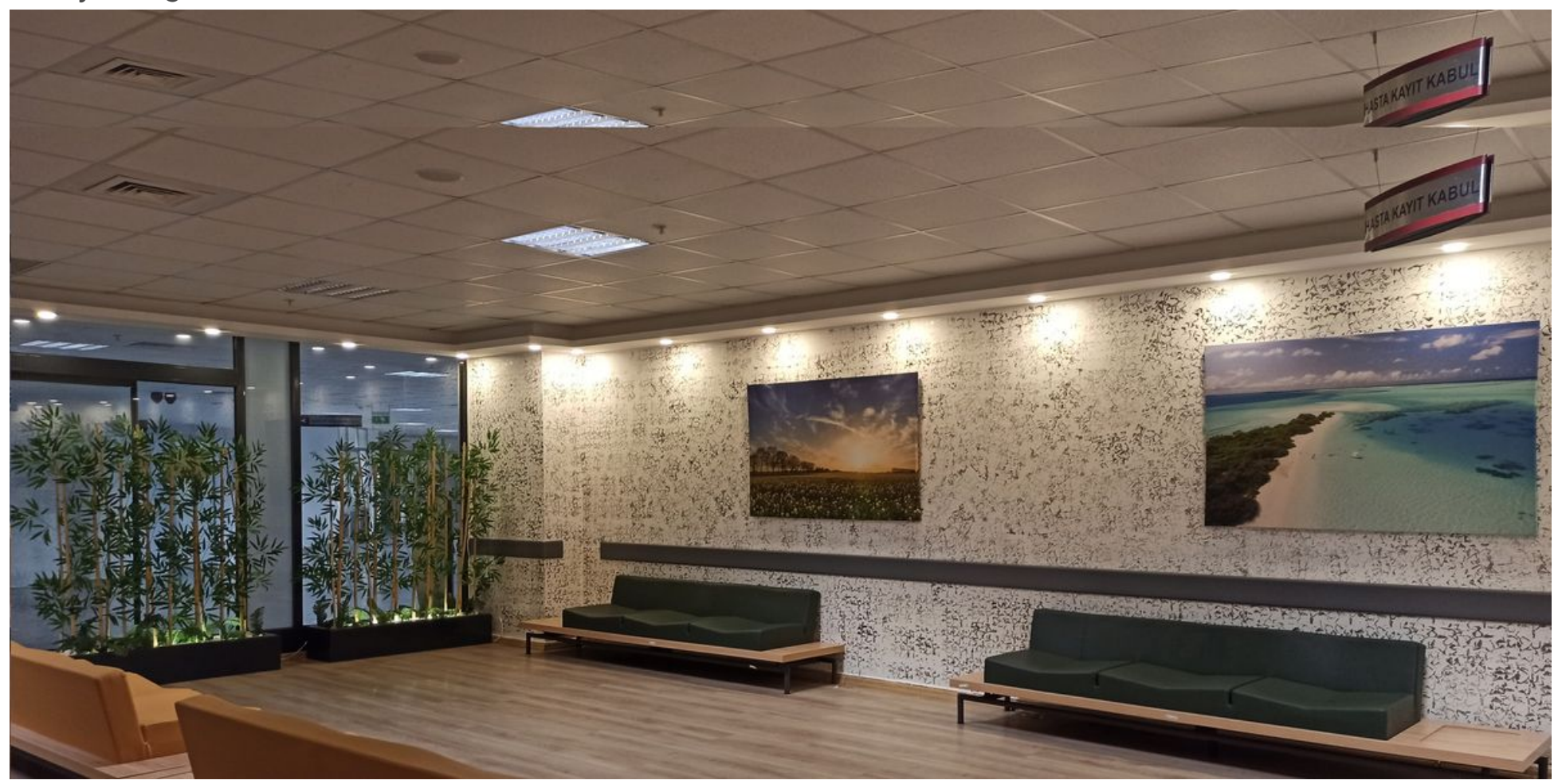

Figure 2

Appearance of the intervention waiting room 


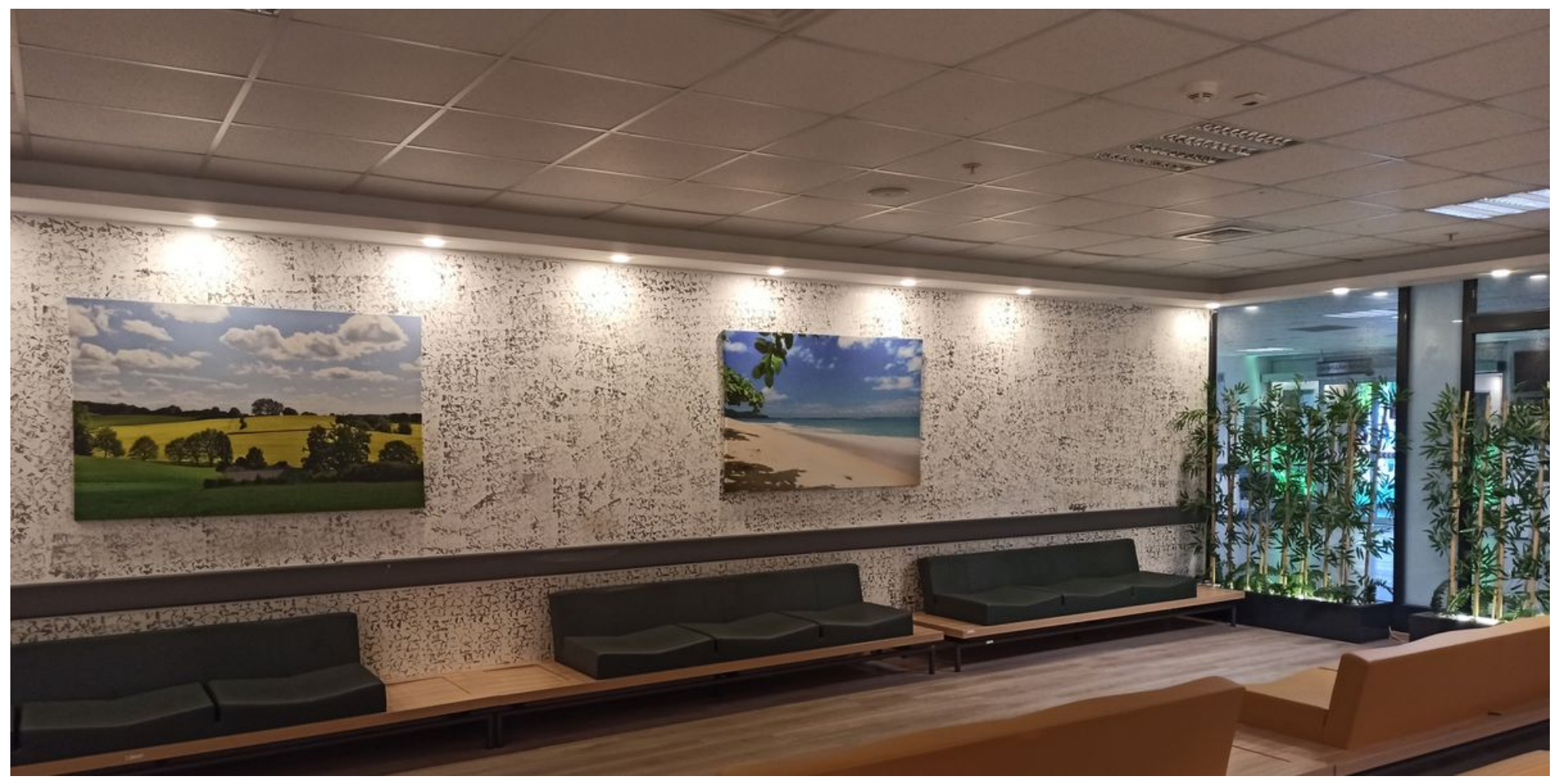

\section{Figure 3}

Appearance of the intervention waiting room

\section{Supplementary Files}

This is a list of supplementary files associated with this preprint. Click to download.

- ESelcukSeber.pdf

- eyyup.pdf

- kubilayKaraboyun.pdf

- nehir.pdf

- okan.pdf

- yakup.pdf 